\title{
Nuclear-Renewable Hybrid Energy Systems: FY17 Stakeholder Engagement and International Activities
}

Shannon M. Bragg-Sitton Richard D. Boardman

October 2017

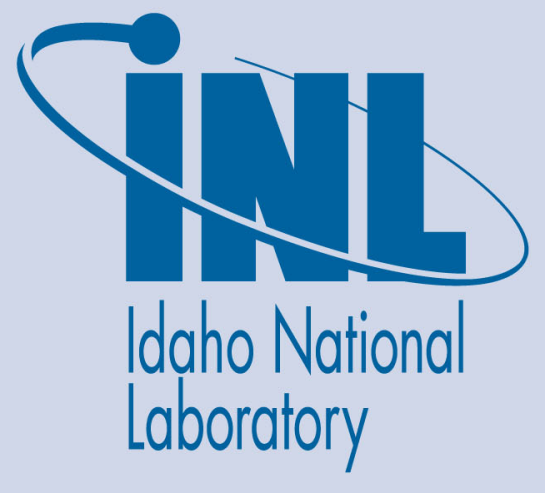

The INL is a U.S. Department of Energy National Laboratory operated by Battelle Energy Alliance 


\section{DISCLAIMER}

This information was prepared as an account of work sponsored by an agency of the U.S. Government. Neither the U.S. Government nor any agency thereof, nor any of their employees, makes any warranty, expressed or implied, or assumes any legal liability or responsibility for the accuracy, completeness, or usefulness, of any information, apparatus, product, or process disclosed, or represents that its use would not infringe privately owned rights. References herein to any specific commercial product, process, or service by trade name, trade mark, manufacturer, or otherwise, does not necessarily constitute or imply its endorsement, recommendation, or favoring by the U.S. Government or any agency thereof. The views and opinions of authors expressed herein do not necessarily state or reflect those of the U.S. Government or any agency thereof. 


\section{Nuclear-Renewable Hybrid Energy Systems: FY17 Stakeholder Engagement and International Activities}

Shannon M. Bragg-Sitton

Richard D. Boardman

October 2017

Idaho National Laboratory Idaho Falls, Idaho 83415

http://www.inl.gov

Prepared for the

U.S. Department of Energy

Office of Nuclear Energy

Under DOE Idaho Operations Office

Contract DE-AC07-05ID14517 


\begin{abstract}
A summary of stakeholder engagement associated with the nuclearrenewable hybrid energy systems (N-R HES) program is provided in this report, highlighting both previous and ongoing interactions for the INL-led program funded via the Crosscutting Technologies Office in the DOE Office of Nuclear Energy. The N-RHES program brings nuclear technology developers and industry users of nuclear energy together to establish a new paradigm for industrial energy production and use. Stakeholder engagement is essential to ensure that the N-R HES project focuses on RD\&D activities relevant to future industry customers (reactor developers, utilities, and commercial industry) and to foster private/public cooperation leading to first-of-a-kind nuclear-utility-industry hybrid projects.
\end{abstract}




\section{CONTENTS}

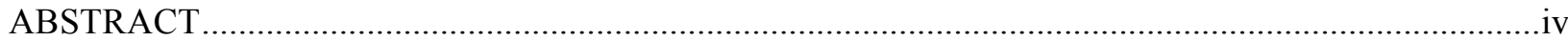

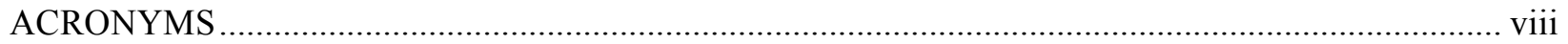

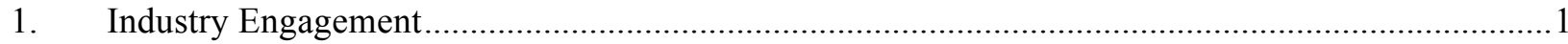

$1.1 \quad$ EPRI Flexible Operations Technical Advisory Group .................................................. 1

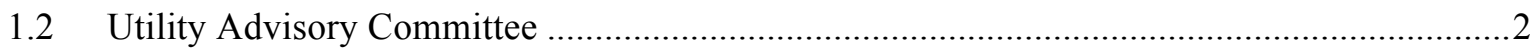

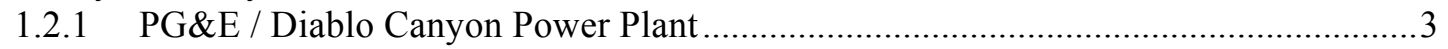

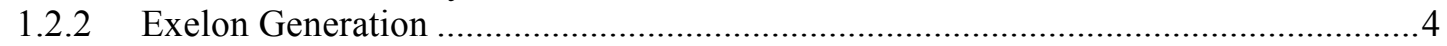

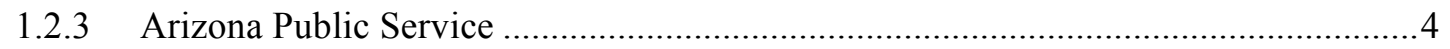

1.3 Committees, Expert Groups and Keynote Presentations .....................................................

1.4 Cooperative Research and Strategic Partnerships...........................................................

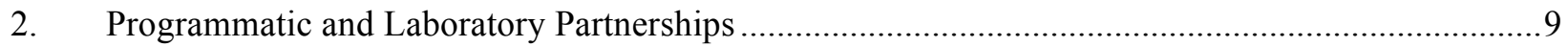

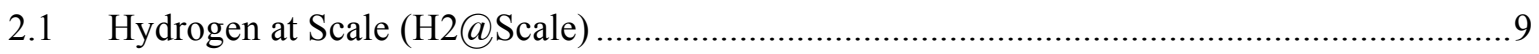

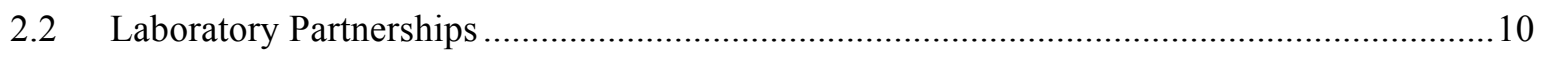

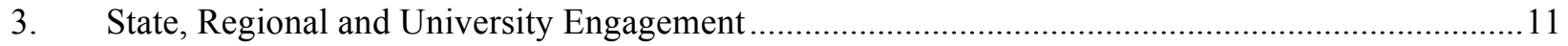

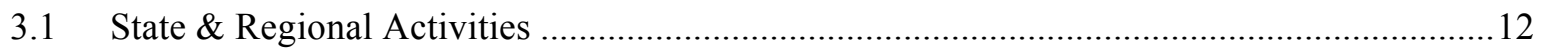

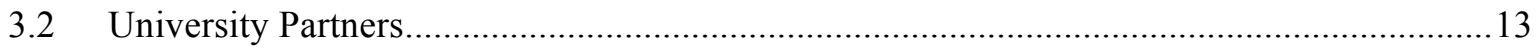

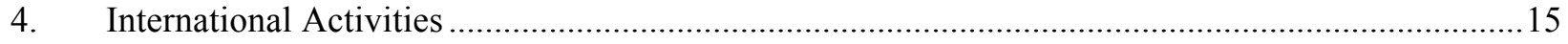

$4.1 \quad$ International Committees / Expert Groups …................................................................ 15

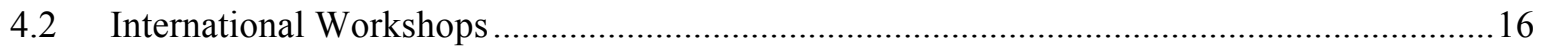

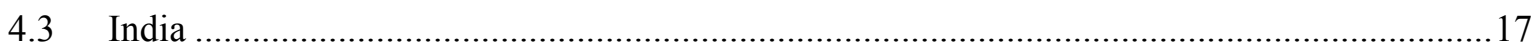

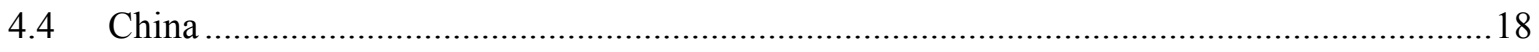

\section{FIGURES}

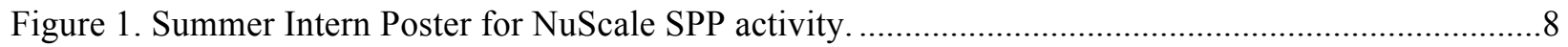

Figure 2. H2@Scale Energy System for Production and Use of Hydrogen ..............................................10

Figure 3. Illustration of opportunities to use nuclear heat to upgrade coal...............................................13 


\section{ACRONYMS}

AMO

ANL

A-NPP

APS

AREVA

AZCC

BEA

BWR

CAES

CAS

CEA

CEO

CNEWG

CRADA

DCPP

DOE

EERE

EPRI

EPSA

ESSAI

FCO

FCTO

FPO

FY17

GAIN

GW-h

GWU

H2@Scale

HES

HTSE

HyS

IAEA

IEA

INET

INL

IP

IP

IPA

ISO

JAEA

JASON

JISEA

LBNL

LCOE

DOE Advanced Manufacturing Office

Argonne National Laboratory

Advanced Nuclear Power Plant

Arizona Pubic Services

(a company name)

Arizona Corporation Commission

Battelle Energy Alliance

Boiling Water Reactor

INL Center for Advanced Energy Studies

Chinese Academy of Sciences

French Alternative Energies and Atomic Energy Commission ("Commissariat à l'énergie atomique et aux énergies alternatives")

Chief Executive Officer

Civil Nuclear Energy Working Group

Cooperative Research and Development Agreement

Diablo Canyon Nuclear Power Plant

U.S. Department of Energy

Energy Efficiency and Renewable Energy Office

Electric Power Research Institute

Energy Policy and Strategic Analysis

Energy Systems Strategies, Assessments, and Integration

Fuel Cycle Options

DOE Fuel Cell Technology Office

Flexible Operations

Fiscal Year 2017

Gateway for Accelerated Innovation in Nuclear

Gigawatt-hours

The George Washington University

EERE Program: Hydrogen at Scale

Hybrid Energy System

High Temperature Steam Electrolysis

Hybrid Sulfur (Thermochemical water splitting cycle)

International Atomic Energy Agency

International Energy Agency

Institute of Nuclear Energy Technology

Idaho National Laboratory

Intellectual Property

Intellectual Property

Intermountain Power Agency

Independent System Operator

Japan Atomic Energy Agency

Group named after Jason, an ancient Greek mythological hero

Joint Institute of Strategic Energy Analysis

Lawrence Berkeley National Laboratory

Levelized Cost of Electricity 


$\begin{array}{ll}\text { LINE } & \text { Leadership in Nuclear Energy } \\ \text { LWR } & \text { Light Water Reactor } \\ \text { MIT } & \text { Massachusetts Institute of Technology } \\ \text { MW-h } & \text { Megawatt-hours } \\ \text { NCSU } & \text { North Carolina State University } \\ \text { NE } & \text { DOE Nuclear Energy Office } \\ \text { NEA } & \text { Nuclear Energy Agency } \\ \text { NEI } & \text { Nuclear Energy Institute } \\ \text { NEST } & \text { Nuclear Energy Sciences and Technology } \\ \text { NEUP } & \text { DOE Nuclear Energy University Program } \\ \text { NGNP } & \text { Next Generation Nuclear Plant } \\ \text { NIC } & \text { Nuclear Infrastructure Council } \\ \text { NOG } & \text { Non-Governmental Organization } \\ \text { N-R HES } & \text { Nuclear-Renewable Hybrid Energy System } \\ \text { NREL } & \text { National Renewable Energy Laboratory } \\ \text { NUC } & \text { National University Consortium } \\ \text { OEDC } & \text { Organizations for Economic Co-Operative Development } \\ \text { ORNL } & \text { Oak Ridge National Laboratory } \\ \text { OSTI } & \text { DOE Office of Scientific and Technical Information } \\ \text { OSU } & \text { Oregon State University } \\ \text { PG\&E } & \text { Pacific Gas \& Electric } \\ \text { PNNL } & \text { Pacific Northwest National Laboratory } \\ \text { PRB } & \text { Power River Basin } \\ \text { PVGS } & \text { Palo Verde Generating Station } \\ \text { PWR } & \text { Pressurized Water Reactor } \\ \text { R\&D } & \text { Research and Development } \\ \text { RAVEN } & \text { Risk Analysis Virtual Environment } \\ \text { RD\&D } & \text { Research, Development, and Demonstration } \\ \text { SARI } & \text { Shanghai Advanced Research Institute } \\ \text { SINAP } & \text { Shanghai Institute of Nuclear and Applied Physics } \\ \text { SMR } & \text { Small Modular Reactor } \\ \text { SOEC } & \text { Solid Oxide Electrolysis Cell } \\ \text { SPP } & \text { Strategic Partnership Project (formerly known as Work for Others) } \\ \text { SRNL } & \text { Savannah River National Laboratory } \\ \text { TAG } & \text { Technical Advisory Group } \\ \text { TEA } & \text { Technical Economic Assessment } \\ \text { TOSU } & \text { The Ohio State University } \\ \text { TW-h } & \text { Terrawatt-hours } \\ \text { UAC } & \text { Utility Advisory Committee } \\ \text { UAMPS } & \text { Utah Associated Municipal Power Systems } \\ \text { UNM } & \text { University of New Mexico } \\ \text { US-JP } & \text { United States - Japan } \\ \text { USTAR } & \text { Utah Science, Technology, and Research } \\ \text { UT } & \end{array}$




\section{Nuclear-Renewable Hybrid Energy Systems: FY17 Stakeholder Engagement and International Activities}

\section{Industry Engagement}

Industrial engagement is a crucial element in the Nuclear-Renewable Hybrid Energy Systems: 2016 Technology Development Program Plan. ${ }^{1}$ Involvement of industry - namely utilities, transmission system operators, reactor vendors and developers, and industrial energy users - in the research and development activities associated with Nuclear-Renewable Hybrid Energy Systems (N-R HES) ensures that the DOE laboratory led research is relevant to industry needs and is grounded in realistic scenarios for subsystem integration, operation, and control. The N-R HES Program is establishing strong ties with industry through a Utility Advisory Committee, Cooperative Research and Development Agreements (CRADAs) and Strategic Partnership Projects (SPPs), and workshops designed to bring industrial stakeholders, researchers, DOE, and other government organizations together to identify energy systems development needs. One goal is to garner cost-shared RD\&D commencing with technology development, systems integration and co-simulation/testing, and pre-commercial demonstrations to reduce the risk of building and operating hybrid energy systems that derive a large portion of their energy from nuclear fission.

The N-R HES program brings nuclear technology developers and industry users of nuclear energy together to establish a new paradigm for industrial energy production and use. Additionally, state and local governments need to be engaged to determine how first-of-a-kind N-R HES may be permitted for construction and operation. This section summarizes key programmatic interfaces with industry as well as outgrowths of those interfaces (i.e. direct industry-funded research and analyses).

\subsection{EPRI Flexible Operations Technical Advisory Group}

The N-R HES concept was first presented to the Electric Power Research Institute (EPRI) Technical Advisory Group (TAG) on Flexible Operations (FPO) of Nuclear Power Plants in February 2016. At that time Dr. Shannon Bragg-Sitton, N-R HES Program Lead, was a new member of the TAG and was asked to present the N-R HES concept as an alternative to flexible operation of nuclear plants - an operational mode that is expected to become more prominent in the U.S. to avoid negative electricity pricing which results from periodic excess generation (e.g. from wind or solar), grid congestion, etc. This initial presentation sparked several discussions with vendors and utilities, with follow-up discussions held with EPRI, Diablo Canyon Nuclear Power Plant (DCPP), AREVA and Westinghouse shortly after the meeting. The EPRI FPO TAG meets two times per year (nominally August and February) within the EPRI Nuclear Power Council meeting; membership includes a large number of utilities and reactor vendors, both domestic and international.

Advances in the N-R HES program have been presented at each FPO TAG meeting since Dr. Bragg-Sitton was made a part of the advisory group. At the February 2017 meeting (held in Charlotte, $\mathrm{NC}$ ), the presentation focused on recent analyses for hybrid energy systems, including evaluation of key industrial thermal energy users that could be coupled with a light water reactor. The most recent meeting was held in Hollywood, Florida in August 2017. Strong support for the N-R HES research was again expressed by members of the TAG, with the Chairman of the PWR Owner's Group offering strong verbal support for the program during the meeting.

Involvement in the EPRI TAG has led to multiple additional discussions on hybrid energy system concepts, ultimately leading to the establishment of the Utility Advisory Committee (UAC) discussed in Section 1.2, which is designed to ensure relevance of the programmatic work to industry as the work

\footnotetext{
${ }^{1}$ The N-R HES program plan, issued in March 2016, is available at https://www.osti.gov/scitech/biblio/1333006.
} 
progresses. Sections $1.3-1.5$ highlight on-site meetings held to aid the N-R HES program leadership in understanding plant operations and limitations, and to further explain the N-R HES concept to corporate leadership and plant operators. In addition, this interaction led to an INL-EPRI coordination meeting focused on hybrid energy systems and hydrogen generation that was held at the EPRI Palo Alto Offices on May 10 (in advance of the UAC kick-off meeting discussed in Section 1.2). This coordination meeting introduced the various INL and EPRI programs in this space, including grid-related initiatives at EPRI, and took the initial steps to identify potential areas of collaboration.

\subsection{Utility Advisory Committee}

A significant number of discussions have been held with utilities regarding the potential for retrofit/repurposing current fleet reactors for hybrid operation to address economic challenges that are currently being faced in some regions around the U.S. and to accommodate the need for flexible operation that results from increasing penetration of renewables. These discussions led the N-R HES program to establish a Utility Advisory Committee (UAC). A charter for the UAC was drafted and a kick-off meeting was held in May 2017. The UAC is tasked with providing advice to the DOE N-R HES Program Manager to assist in the development and execution of a program focused on utilization of the current fleet of LWRs, and the next generation of reactors, beyond the electricity sector. While new reactor plants currently in the design phase are expected to be able to most easily adopt new operational paradigms that include the use of both thermal and electrical energy from baseload fission generation systems (e.g. to support industrial applications), there are many opportunities for repurposing the current fleet of reactors that can be considered to improve operational flexibility and plant economics, and to begin to address the reduction of harmful emissions from the industrial sector. Demonstration of "hybrid" system concepts in the current fleet will also enhance opportunities for the next generation of reactors as the electricity-only paradigm for nuclear plants is broken down and regulatory and safety concerns are addressed.

The Committee will advise the N-R HES Program Manager on a potential path forward for the current fleet with regard to diversifying plant output via hybrid energy system approaches. This guidance will ensure that the DOE-funded research and development program is appropriately focused on the most relevant off-take industries for current and future reactor plants and realistic integration options (thermal and electrical), with consideration given to technical performance, safety, and regulatory guidelines. The Committee will provide specific advice on a number of key subjects, as listed below, and will review program progress and provide recommendations in written reports. Primary UAC responsibilities include:

1. Develop a summary of regional motivations for flexible or hybrid operation of nuclear plants, with an initial focus on the current LWR fleet (in coordination with N-R HES programmatic staff).

2. Develop a summary of regional industrial operations of interest to plant owners/operators for repurposing of their respective fleets.

3. Define general operational capabilities and constraints for operating PWRs and BWRs as they relate to non-grid applications of both thermal and electrical energy produced by the plants. Capabilities and constraints should address both primary and secondary systems.

4. Summarize anticipated regulatory challenges to non-grid applications of nuclear energy for the current fleet (retrofit/repurposing) and future fleet applications.

5. Review feasibility of candidate regional opportunities for nuclear plants to provide energy to industrial applications in coordination with other generators in those regions. Example applications may include, but are not limited to, water desalination, hydrogen generation (as a final product or within a broader industrial process), methanol and polymers production, biofuels production, steel manufacturing, ammonia production, etc.

6. Summarize utility perspective and interest in energy storage and review the feasibility of, and business case for, energy storage relative to power generation and secondary markets. Example applications may include, but are not limited to, pumped hydro, large compressed air, GW-h 
battery installations, GW-h scale thermal energy storage, and TW-h chemical energy storage (e.g. hydrogen).

7. Provide, as requested, guidance on a long-term program for the demonstration, deployment, and regulatory approval of nuclear hybrid system applications.

8. For the selected high priority regional opportunities, provide input on general tasks, schedule and responsibilities for commercial reactor demonstrations, as appropriate.

9. Provide additional insight, as needed, from the perspective of the nuclear plant owner/operator to ensure continued relevance of DOE-funded research and development activities.

A UAC kick-off meeting was held at the EPRI offices in Palo Alto, CA in May 2017. Note that all costs associated with UAC participation, including time and travel, are borne by the member's organization. Current committee membership includes EPRI, Exelon Generation, Arizona Public Service (APS, operating owner of the Palo Verde Generating Station [PVGS]), Pacific Gas \& Electric (PG\&E, which operates the Diablo Canyon Power Plant), and Southern Nuclear; additional utilities have expressed interest via the EPRI FPO TAG. UAC members are selected on the basis of their technical knowledge of nuclear plant, regional grid, and/or regional industrial energy needs and processes as well as their decision-making positions in their respective companies. Committee members may nominate additional members to the Program Manager, including, for example, independent system operators (ISO) responsible for grid interconnections with load-balancing authority.

Participants to the UAC kick-off meeting included one or more representatives from each of the member organizations, including EPRI representatives from nuclear generation, hydrogen generation, and the Integrated Grid projects; the DOE-NE program manager for N-R HES; and a representative from the DOE Office of Energy Efficiency and Renewable Energy Fuel Cell Technologies Office, which leads the related Hydrogen at Scale Program. A key decision taken at the initial meeting was to conduct focused pilot case studies in FY18, selecting two currently operating nuclear plants as focal points to assess the potential repurposing of existing LWRs to applications beyond the electric grid; positive results from such studies could lead to concept demonstration at an operating nuclear plant. It was agreed that pilot studies would focus on PVGS in Arizona, operated by APS, and an Exelon Generation owned and operated plant (specific plant to be determined in early FY18).

\subsubsection{PG\&E / Diablo Canyon Power Plant}

Leadership from the Diablo Canyon Power Plant (DCPP), operated by PG\&E, initially engaged the N-R HES Program leadership in Spring 2016. At that time, DCPP was keenly interested in pursuing investigation of loosely coupled hybrid systems for retrofit of the two DCPP units to manage an anticipated need to flex power output to the grid by as much as $300 \mathrm{MWe}$ in the next 5 years due to increasing penetration of variable renewables. DCPP, in coordination with EPRI, followed-up by approaching PG\&E management to determine whether there was interest in conducting specific investigations on electrical integration of the plant (behind the grid) with selected industrial processes. Note that although PG\&E later made the decision not to pursue license extension for the two DCPP plants (Summer 2016), PG\&E has remained in discussion with the N-R HES program regarding the potential for HES applications in general (current fleet and/or future plants) and has offered insight as to how behind the grid integration of large scale desalination or other electrical energy uses might be accomplished.

A small group from the N-R HES program leadership and modeling and simulation staff (S. Bragg-Sitton, R. Boardman, C. Rabiti, J.S. Kim) met with DCPP staff at the plant in November 2016 to discuss plant integration with an onsite reverse osmosis desalination plant (current operation).

Discussions covered potential challenges associated with operation of a larger scale desalination plant that could support broader community water needs or plant integration with another industrial energy user (possibly thermally integrated). The decision made by PG\&E to not pursue license extension for the two DCPP units changed the nature of these discussions relative to what was originally anticipated; however, DCPP is providing data (where possible and relevant to the broader LWR fleet) and feedback on 
integrated energy system approaches that could aid continued operation of other plants in the current LWR fleet.

\subsubsection{Exelon Generation}

N-R HES program leadership (S. Bragg-Sitton and R. Boardman) and other key leaders from the DOE national laboratories and industry were invited to participate in the Exelon-organized Consortium on Nuclear Plant Repurposing at Exelon Headquarters in Chicago, IL (May 4-5, 2017). Organized by the Corporate Strategy division of Exelon, this invite-only consortium focused on the potential for repurposing of existing Exelon plants to improve market viability. Many discussions with the Exelon Corporate Strategy team led to this interaction, where nuclear hybrid energy systems, incorporating a variety of industrial applications, were presented as potential options to improve the economic performance of Exelon owned and operated nuclear plants that are currently under duress. This Consortium engaged corporate and nuclear operations leadership at Exelon as well as subject matter experts in plant operations to consider plant utilization beyond the electric grid. The presentations and brainstorming discussions held during the Consortium meeting established buy-in from a larger group at Exelon for plant repurposing.

A working meeting was held between Exelon, EPRI, INL and ANL in October 2017 to further discuss and clarify the UAC-proposed pilot case study to evaluate use of an Exelon nuclear plant operating in the U.S. Midwest to support an industrial application in addition to electricity production. The scope of the study will include identification of opportunities to integrate with the broader Midwestern industrial and energy ecosystem (e.g. agriculture, ethanol production, steel production, aluminum refining, oil refining, etc.). These analyses will be performed with the assistance of Exelon, which operates multiple nuclear plants in the U.S., and with consultation from EPRI. Results of these analyses, which will be documented in an FY18 programmatic milestone, will support Exelon's decision to proceed on proposed repurposing one or more existing plant that is currently seeing the impacts of generator and load variability. Positive results from the dynamic analysis and simulation task may lead to a future demonstration of the integrated system technology. While the case study will focus on a specific plant, it will be designed such that the results will more broadly support the current fleet of LWRs and potential future builds (e.g. NuScale Power, various advanced reactor developers).

\subsubsection{Arizona Public Service}

Leaders in the N-R HES program were invited to participated in the EPRI FPO Engineering Impacts Assessment Meeting hosted by Palo Verde Generating Station (PVGS) in February 2017. INL was invited to present the N-R HES concept as an alternative to flexible operation for PVGS, which is anticipating the need to flex plant output by several hundred MWe in the relative near term. The assessment meeting included leadership from both PVGS and Arizona Public Service (APS), the majority owner of PVGS (which has 7 owners in total).

A follow-on meeting was held with leadership from APS in September 2017 to discuss the details of the proposed analysis case for FY18 that will assess the potential for hybridization of PVGS via electrical integration. There is currently no consideration of possible thermally integrated energy users. The multiowner nature of PVGS complicates proposal of more dramatic changes to plant operation. Initial discussions focused on treatment of brackish water that could be used for onsite cooling water as the most desirable option for hybridization. However, this process would only account for 10-50 MWe of electricity usage, whereas seasonal peaks in solar PV that drive electricity prices negative and may force flexible operation of PVGS by as much as $500 \mathrm{MWe}$. Hence, discussions were also initiated to consider electrical or electrical-to-thermal energy storage and hydrogen generation (or hydrogen for an off-taker market). The scope of the FY18 study is currently being finalized. As noted for Exelon, the planned analyses will be performed with the assistance of APS and with consultation from EPRI. Results of these analyses, which will be documented in an FY18 programmatic milestone, will support APS's decision to proceed on additional utilization of PVGS. Positive results from the dynamic analysis and simulation task 
may lead to a future demonstration of the integrated system technology. While the case study will specifically focus on PVGS and the Southwestern region, it will be designed such that the results will more broadly support the current fleet of LWRs and potential future builds (e.g. NuScale Power and various advanced reactor developers).

\subsection{Committees, Expert Groups and Keynote Presentations}

Members of the N-R HES program have been called on to serve on various committees, expert or advisory groups, and to deliver various keynote presentations at U.S. and international conferences in addition to the EPRI FPO TAG discussed in Section 1.1. These opportunities establish DOE and national laboratory leadership in advanced energy systems and ensure broader dissemination of the DOE-funded research. Several of these roles and opportunities are further summarized here. In many cases these activities are not funded directly by the N-R HES program but are the result of programmatic leadership for non-electric uses of nuclear fission technology; funding for participation is, in many cases, provided by complementary, cooperative programs that enhance the impact of the N-R HES program. Additional information on programmatic collaboration is provided in section 2 .

DOE EERE Hydrogen at Scale (H2@Scale): The EERE H2@Scale program is the primary point of EERE collaboration with the DOE-NE funded N-R HES program. Dr. Richard Boardman and Dr. Shannon Bragg-Sitton sit on the Steering Committee for H2@Scale; Dr. Boardman additionally leads the pillar for industrial uses of hydrogen as well as integration of high temperature water-spitting technologies. Boardman visited several key industries and university stakeholders in FY17 who have interest in using hydrogen for chemicals and steel production. Three workshops hosted by EERE H2@Scale were held in FY17 (Denver, Washington D.C., and Houston) to help formulate a Research, Development and Demonstration (RD\&D) Roadmap for hydrogen production and end users. The Roadmap addresses: (1) R\&D Needs for Industrial Utilization of Hydrogen and (2) the Cost of Producing Hydrogen Using a Nuclear Power Plant Coupled to High Temperature Steam Electrolysis (HTSE). Additional H2@Scale workshops are planned for Long Beach, CA (November 6, 2017), and Houston, TX ( April 2018).

International Small Modular Reactor and Advanced Reactor Summit (March 2017): Dr. Shannon Bragg-Sitton participated as an invited speaker in the 2017 International Small Modular Reactor and Advanced Reactor Summit held in Atlanta, GA. This forum brings together advanced and small modular reactor developers, researchers, and energy market experts from over 15 countries, providing a unique venue to assess technology development status and emerging market needs for advanced nuclear energy systems. Additional information on the Summit can be found at http://www.nuclearenergyinsider.com/international-smr-advanced-reactor/. The invited presentation highlighted recent work in the N-R HES program, with a specific focus on the industrial thermal energy use opportunities, as documented in the study that was completed jointly by INL and NREL (via funding from DOE-NE and EERE, respectively) that was released in December $2016 .^{2}$ The presentation piqued the interest of the industry and researcher participants, spawning various fruitful discussions that could result in future collaborations.

Women in Nuclear Annual Conference (July 2017): Dr. Shannon Bragg-Sitton (INL), Dr. Askin Guler (ORNL) and Dr. Carol Smidts (The Ohio State University) participated in an invited presentation and panel session on nuclear hybrid energy systems at the annual Women in Nuclear meeting in San Francisco, CA on July 24. This session brought the concept of N-R HES to a broader audience than other professional society conference presentations (e.g. American Nuclear Society), including a large number of nuclear industry representatives from both developers and utilities.

\footnotetext{
${ }^{2}$ McMillan, C., et al., Generation and Use of Thermal Energy in the U.S. Industrial Sector and Opportunities to Reduce its Carbon Emissions, available at https://www.osti.gov/scitech/biblio/1335587.
} 
Fourth Annual Intermountain Energy Summit, August 8-9, 2017: The Intermountain Energy Summit is organized by the Idaho Falls Post Register with sponsors including INL, industry, and government stakeholders in the Intermountain West. The theme of the 2017 summit was Future Energy Portfolios of the Intermountain and Pacific Northwest Regions: What will the future mix of energy supplies for the Western U.S. look like? How are utilities planning for the inevitable shifts in energy sources? Dr. Richard Boardman participated on a panel considering emerging unique applications for nuclear energy. Joining Boardman were Michael Hagood (INL, Panel Moderator), Robin Rickman (Terrestrial Energy USA), Mark Peres (Fluor), and Ashley Finan (Nuclear Innovation Alliance). See http://intermountainenergysummit.com for additional details.

2017 JASON Summer Study: Dr. Richard Boardman was asked to meet with academic leads for a 2017 JASON Summer Study titled Advanced Technologies, Evolving Markets, and Implications for Evolving Nonproliferation and Export Policy. JASON is a non-profit group of distinguished university professors and emeritus professors who meet annually to study energy, environment, and national security tropics of concern by the U.S. government and Department of Defense. JASON currently is run through the MITRE Corporation.

Boardman first met with the JASON leads June 22-23 in La Jolla, CA at the General Atomics Offices to address the following questions:

- Can non-baseload nuclear energy provide a sustainable, cost-competitive source of energy for industrial manufacturing?

- What are the technical and economic considerations?

- What are the environmental and energy security benefits?

- Can the United States possibly benefit in a global market?

- How can process technology and nuclear technology innovation be integrated more effectively and can this increase the U.S. export markets of nuclear energy?

- What is the possible scale of economic and social impacts?

Following the initial discussion, a number of N-R HES program documents available on OSTI (www.osti.gov) were referred to the study group. The report on this subject will be available by the end of 2017; the study was specifically organized by the Energy Systems, Strategies, Assessments, and Integration (ESSAI) Program, also under DOE-NE.

United States Nuclear Infrastructure Council (U.S. NIC, October 3-4, 2017): A special nuclear energy leadership summit focused on American manufacturing and the U.S. supply chain was organized by the U.S. NIC in Idaho Falls, ID in October 2017. Dr. Shannon Bragg-Sitton was invited to deliver a presentation on how hybrid energy system approaches may be applied to meet future energy demands within a panel session on "Overarching Issues" associated with deployment of advanced nuclear energy systems. This presentation triggered follow-on discussions with the President and CEO of the Utah Associated Municipal Power Systems (UAMPS) regarding hybrid configurations that might be considered for the planned NuScale Power reactor prototype deployment. Discussions also followed with AREVA with regard to experimental systems operated by AREVA in Germany that may be of use in demonstrating some aspects of hybrid energy systems applications for LWR technologies.

2017 Fuel Cell Seminar (November 7-9, 201): Dr. Richard Boardman has been invited to speak on the subject of using nuclear energy to produce hydrogen at the upcoming Fuel Cell Seminar that will be held in Long Beach, CA. The Fuel Cell Seminar aims to inform private and federal stakeholders on the progress of hydrogen production technology, storage and delivery infrastructure, transportation, and industrial use of hydrogen. 


\subsection{Cooperative Research and Strategic Partnerships}

INL supports DOE-approved Cooperative Research and Development Agreements (CRADAs) and Strategic Partnership Projects (SPPs) with nuclear reactor and associated technology developers, much of which derives from communication of the programmatically supported work to evaluate and develop nuclear hybrid energy systems. In return, CRADA/SPP projects increase the expertise of the INL N-R HES Program leads. In 2017, INL continued to support CRADAs/SPPs related to potential HES implementations with TerraPower, NuScale Power, and Terrestrial Energy. A series of technical/economic analysis (TEA) were completed to establish the business case for supplying steam, heat, and electricity to 1) tightly coupled systems, 2) combined heat and power concepts, and 3) full hybrid operations where the nuclear plant arbitrages energy to optimize plant revenue. INL is in various stages of discussion on CRADA agreements for technology development or TEAs for X-energy, AREVA, General Electric, and Westinghouse.

Although this work is funded entirely by the CRADA/SPP partners, and is segregated from the DOE N-R HES Program work, it leverages the capabilities that have been established under either LaboratoryDirected R\&D or direct programs. After nearly 20 years of studying nuclear energy integration with industrial processes, INL has become the technical authority on the best opportunities for application of LWR and high temperature reactors to the process industry. INL mainly uses ASPEN ${ }^{\circledR}$ and $\mathrm{HYSYS}^{\circledR}$ to develop detailed designs for nuclear plant integration with convention and revolutionary process applications. INL has further established relevant databases for estimating capital and operating costs of hybrid energy plants. Project cash-flows are then predicted based on project-specific investment conditions and discount rates for loans and inflation. This follows the pattern established under the DOEsponsored Next Generation Nuclear Plant (NGNP) project.

In some CRADAs/SPPs Intellectual Property (IP) has been generated based on the understanding gained through process modeling and recommendations given by the INL team. INL Technology Transfer manages the IP interests of DOE, BEA, and the associated partners. Examples of technologies that have been developed to better facilitate the use of nuclear energy include a multi-stage eutectic salt thermal energy storage buffer that will better facilitate heat delivery to a high temperature chemical process. A provisional patent has been filed by INL for this technology concept. Terrestrial Energy has committed resources to co-develop this technology. A second example is the development of a novel approach to use nuclear energy provided by a TerraPower Traveling Wave or Molten Salt Reactor to convert biomass and coal into higher value chemicals and carbon-based products. TerraPower has built a small pilot plant to advance this particular application.

Another illustrative example is a SPP with NuScale Power that employs the University of Wyoming as a partner in a study led by INL to determine the value of using the NuScale SMR to dry and detoxify coal in the Wyoming Powder River Basin (PRB). This application can increase the heating value of PRB coal while is also drives off mercury. Both changes improve the heat rate of coal-fired power plants, resulting in significantly higher electricity output at the coal-fired power plant, and thus helping the plants avoid expensive upgrades to manage toxic pollutant emissions. A poster entitled Atomic Coal (Figure 1) was prepared by an INL Summer Intern and presented at the 2017 INL Summer Internship Research Outcomes meeting. 


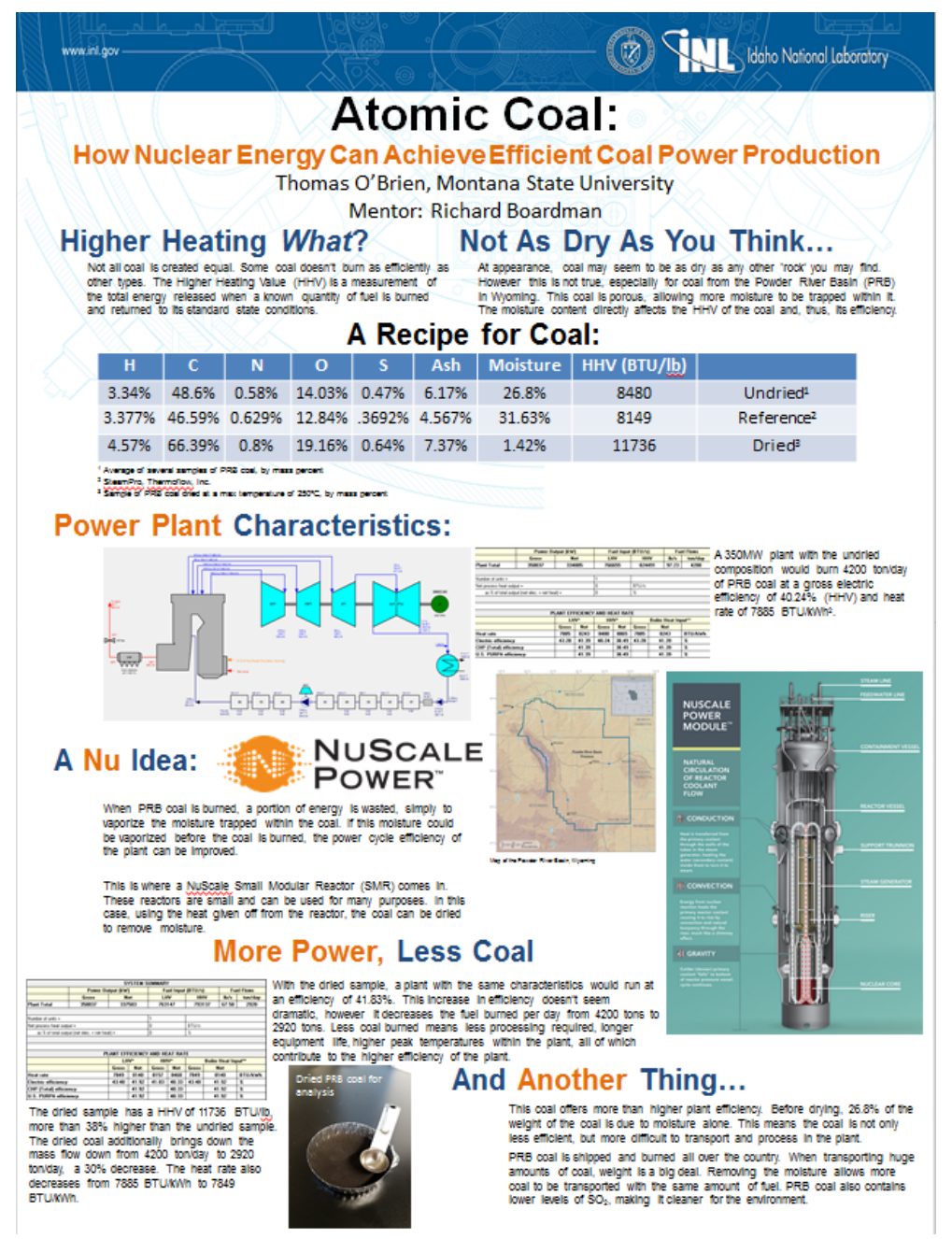

Figure 1. Summer Intern Poster for NuScale SPP activity.

In recent years, CRADAs that consider the value of nuclear energy have been executed with commercial industries and the State of Wyoming. In 2017, several proposals were submitted to the DOE Advanced Manufacturing Office (AMO) Funding Opportunity Announcement for Industrial Uses of Hydrogen, and the DOE Fuel Cell Technology Office (FCTO) H2@ Scale CRADA Call to support National Laboratory R\&D activities. The following proposals, which are related to the NE-funded $\mathrm{N}-\mathrm{R}$ HES work in some fashion, are awaiting funding decisions

- Midrex Steel / INL / Michigan Technical University: AMO FOA Proposal. Producing Direct Reduced Iron using Co-Electrolysis, powered with a clean energy source such as a nuclear reactor.

- BayoTech / University of Utah / INL / PNNL: AMO FOA Proposal. Producing Hydrogen for Direct Reduced Iron in a Suspension Burner for direct application to an electric arc furnace, each powered with a clean energy source such as a nuclear reactor.

- INL / University of Wyoming / Massachusetts Institute of Technology: AMO FOA Proposal. Producing Ethylene and Fuels Using a Proton-Conducting Electrochemical Catalytic Processes, powered with a clean energy source such as a nuclear reactor.

- $\quad$ Southern Company / Xcel / Exelon / INL / NREL / ANL: H2@Scale CRADA Proposal. Regional Case for Producing Hydrogen Using a LWR. 
- Exelon / INL / NREL / ANL: H2@Scale CRADA Proposal. Case Study for Hydrogen Production, Delivery, and Use by Industry via the Use of an Exelon Nuclear Reactor, to collaborate directly with the DOE-NE N-R HES pilot case study for a hybrid plant located in the Midwest (see section 1.2.2).

- State of Utah (Millard Country Economic Development) / INL / PNNL / NREL: H2@,Scale CRADA Proposal. Organizing Discussions with State and Industry for Hydrogen Production, Storage, and Markets Cases in Utah. The following have committed to participate: NuScale Power, Utah Associated Municipal Power Systems (UAMPS), Intermountain Power Agency (IPA), and Magnum Gas.

- $\quad$ TerraPower / INL / PNNL: H2@,Scale CRADA Proposal. The Case for TerraPower Nuclear Reactor Coupling with High Temperature Electrolysis and Electrochemical Processes that Produce Hydrogen as a Direct or an Indirect Product.

- Greenway / Southern Company / Terrestrial Energy / INL / SRNL: H2@,Scale CRADA Proposal. Development of Hybrid Sulfur Iodine Thermal Chemical Process for Hydrogen Generation Using a Molten Salt Nuclear Reactor.

- Nikola Motors / INL: H2@,Scale CRADA Proposal. The Case for Operating Hydrogen Generation and Filling Stations along Interstate Corridors Using Excess Power from the Grid.

\section{Programmatic and Laboratory Partnerships}

Multiple partnerships, collaborations, and coordination of activities with other DOE programmatic research maximizes the impact of NE-funded N-R HES research. Key collaborations are highlighted in this section, although additional, less formal partnerships are also emerging (e.g. with the Gateway for Accelerated Innovation in Nuclear [GAIN] Initiative, the DOE-NE Fuel Cycle Options Campaign [FCO] and Energy Systems Strategies, Assessments, and Integration [ESSAI]).

\subsection{Hydrogen at Scale (H2@Scale)}

Under the EERE and NE Collaboration on Integrated Energy Systems, the main focus in 2017 has been with the Fuel Cell Technology Office (FCTO) under the H2@Scale DOE cross-cutting program. H2@Scale is one of the DOE Cross-Cutting Programs rising from the 2016 DOE Big Idea Summit. $\mathrm{H}_{2} @$ Scale proposes to expand hydrogen production in the U.S. using the complement of energy sources shown in Figure 2. Among various considerations, it aims to use nuclear energy as a reliable, low-cost source of heat and electricity for high-temperature water splitting.

Drs. Richard Boardman and Shannon Bragg-Sitton support weekly meetings of the H2@Scale Analysis Team. The Analysis Team is led by NREL (Mark Ruth), and is mainly supported by ANL (Dr. Amgad Elgowainy), and Lawrence Berkeley National Laboratory (LBNL, Dr. Max Wei). INL reviews the analyses completed by the NREL/ANL/LBNL team, and conducts additional analysis for nuclear hydrogen production hybrid energy systems under the N-R HES Program. INL reports are sent to the H2@Scale Analysis Team and the FCTO office. 


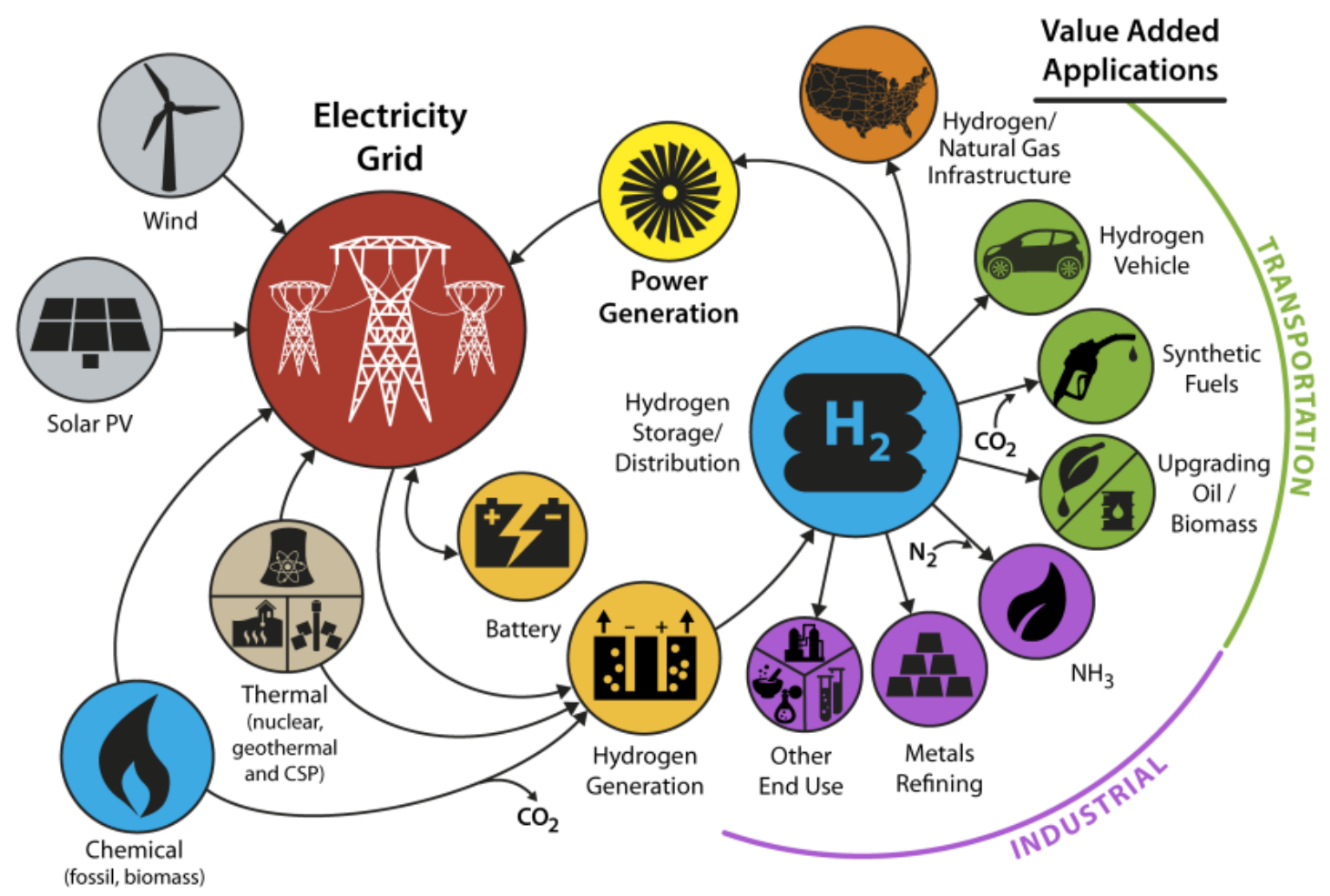

Figure 2.H2@Scale Energy System for Production and Use of Hydrogen

(Credit: Dr. Bryan Pivovar, NREL)

\subsection{Laboratory Partnerships}

The N-R HES program accomplishes the mainstream programmatic work by engaging expertise at multiple national laboratories. While program leadership resides at INL, development of tools and components in the modeling and simulation work, market analysis, stakeholder engagement, etc. are activities that are shared across multiple laboratories. DOE-NE funded N-R HES research is conducted by INL, ORNL, and ANL, and NREL; support to common programmatic objectives is provided via funding from DOE-EERE. This multi-laboratory team enables program staff access to a much greater base of expertise and capabilities. Experimental activities for N-R HES are primarily focused at INL as a laboratory for nonnuclear demonstration of HES concepts is being developed to complement other programmatic investments (e.g. EERE-supported demonstration of HTSE for hydrogen generation). These activities will, however, leverage data linkages with NREL and other laboratories to access additional hardware rather than duplicate test facilities.

The N-R HES program is tied to EERE Program Offices through a formal/informal EERE and NE Collaboration on Integrated Energy Systems. NE and EERE received Congressional Direction in FY15, and FY16 to analyze industrial-scale integrated energy systems. Based on the congressional direction and stakeholder input, EERE and NE agreed to initially examine nuclear-renewable hybrid energy systems (hence, N-R HES). The collaboration has produced several reports, including a capstone study on the generation and use of thermal energy in the U.S. Industrial Sector. ${ }^{3}$ The joint analyses by INL and NREL found that nuclear plants can effectively modulate heat between power production and heat use by an industrial consumer. In FY17, this collaboration began focusing on N-R HES for hydrogen production as

\footnotetext{
${ }^{3}$ McMillan, C., et al., Generation and Use of Thermal Energy in the U.S. Industrial Sector and Opportunities to Reduce its Carbon Emissions, available at https://www.osti.gov/scitech/biblio/1335587.
} 
an opportune hybrid case. In consideration of the regional case studies for Exelon and APS, the FY18 collaboration may also include other top chemicals produced in the U.S.

The N-R HES program has also led to a collaboration with Savannah River National Laboratory (SRNL) on the development of the hybrid sulfur thermochemical process for splitting water to produce hydrogen and oxygen. INL and SRNL and are working with Southern Company and Greenway Energy to develop electrolysis and catalysts for this sulfuric-acid generation and decomposition cycle. The cycle is amenable to a high-temperature nuclear reactor, and is suitable for dynamic operation to provide hybrid energy systems benefits. Support for this activity will be derived under the HydroGEN Energy Materials Network and, if selected for funding, by the H2@Scale CRADA.

In 2017 a concept that derived from the successful work conducted via the N-R HES program led to submission of a DOE Big Idea that was elevated to the $4^{\text {th }}$ DOE Big Ideas Summit that was held in Washington, D.C. in March 2017. Entitled Nuclear Energy Reimagined (NER), the concept proposes establishing hybrid nuclear energy as the cornerstone for energy security, reliability, and sustainability. A summary of the proposed NER program is included below.

The goal of this [NER] initiative is to overcome the technical, economic, and institutional barriers that inhibit wider use of nuclear energy in coordinated energy systems, both centralized and distributed (viz., poly-generation and hybrid energy systems). New and transformational computational tools that are now available allow the previously impossible modeling and simulation of materials and systems behaviors at and away from equilibrium, leading to technologies that will be derived from a first-principles understanding to enable optimal use of fission-generated heat and radiation to produce electricity, drive novel industrial processes, and/or catalyze chemical reactions. Advanced manufacturing methods, facilities, and operations developed with regulatory compliance by design will facilitate time and cost reductions for the design, qualification, and fabrication of nuclear system components.

Development of the Big Idea was a multi-laboratory effort that included INL as lead, with ORNL, ANL, PNNL, and LANL as supporting contributors; additional laboratories expressing interest in joining the team moving forward included NREL, NETL, BNL, LLNL, and SRNL. DOE-NE was identified as the lead DOE HQ steward for the concept, with EERE FCTO, EERE Advanced Manufacturing Office, Office of Science, and Fossil Energy offering additional support. While the NER concept is not currently funded as a stand-alone program, many existing programs have been identified across that DOE complex that represent one or more aspect of the larger NER proposal. Attempts are being made to ensure communication across these potentially related programs to establish a larger umbrella that may be capable of achieving the NER vision.

\section{State, Regional and University Engagement}

The Nuclear-Renewable Hybrid Energy Systems: 2016 Technology Development Program Plan portends scaled demonstration(s) of nuclear hybrid energy systems by 2022, and a full commercial demonstration by $2027 .{ }^{4}$ Success with these activities requires engagement of private and government stakeholders, specifically State and Local (County) Governments who are responsible for economic development and public health. Because commercial projects are dependent on region-specific resources, business markets, and infrastructure, it is incumbent on the N-R HES program to engage States in technical-economic studies. In addition, State engagement is needed to understand State-specific industrial project approval and environmental permitting processes.

University engagement is also beneficial to the program for several reasons, including access to technical expertise, access to enabling innovations, and development of scientific, engineering, and operations workforce. These benefits are being realized through engagement of summer interns and

\footnotetext{
${ }^{4}$ The N-R HES program plan, issued in March 2016, is available at https://www.osti.gov/scitech/biblio/1333006.
} 
postdoctoral researchers at the various laboratories involved in the research and INL alignment of the National University Consortium (NUC) and the INL Center for Advanced Energy Studies (CAES) with N-R HES research objectives.

\subsection{State \& Regional Activities}

State advocacy for nuclear energy is founded on economic development and affordable, reliable energy for State residents and industry. These two are inextricably related. State and Federal policies also can impact energy choices. Application of nuclear energy in the Intermountain Region is driven by all of these factors; therefore, INL has established close relationships with Idaho and surrounding States in the Western United States. Meetings with State Energy Offices and Business Development councils are coordinated through the Laboratory Director where Michael Hagood is the INL Manager for Government and Stakeholder Relationships.

Four States have been especially interested in nuclear energy and its industrial applications: Idaho, Wyoming, Utah and Arizona. Specific interactions with these states are summarized below.

- The Idaho Leadership in Nuclear Energy (LINE) Commission was established to aid the launch of a robust and expansive nuclear industry sector in the state. ${ }^{5}$ The commission is anchored by INL and consists of more than 20 firms that share its vision. Members of LINE Commission are appointed by and serve at the pleasure of the Governor. Dr. Shannon Bragg-Sitton, N-R HES Program Lead, was appointed to serve on the LINE 3.0 Subcommittee on Research, Development, Demonstration, and Deployment beginning in Spring 2017.

- INL supports a number of levels of engagement with the State of Wyoming. The University of Wyoming (the State's only university) recently joined CAES, with an express interest in development of applications in nuclear energy to upgrade fossil and trona resources in the State and to enhance the build-out of renewable energy. The Wyoming Business Council has participated in numerous meetings to discuss this topic. In 2012, a Joint Senate/House Subcommittee was formed to explore the potential to develop and use nuclear energy and nuclear supply chain technology. Dr. Richard Boardman was asked to testify before the Subcommittee. This led to Legislature funding an INL study in 2012: The Feasibility of Value-Added Products from Cogeneration and Hybrid Energy Systems in Wyoming. ${ }^{6}$

Michael Hagood and Dr. Richard Boardman currently manage the ongoing dialog with Wyoming State energy business entities, including the School of Energy Resources at the University of Wyoming. A discussion was recently held with the Wyoming Natural Resources Policy Director (Jeremiah Reimann); Figure 3 shows a graphic that was used to highlight various opportunities to use nuclear energy as a non-emitting energy source to convert coal into higher value products.

- The State of Utah Office of Energy Development and INL hold frequent meetings. Alair Emery, Manager of Advanced Energy Technologies and Economic Development, is specifically tracking the State's opportunities and interest in nuclear energy. Dr. Richard Boardman is working with her office in regard to the use of nuclear energy for fossil resource production and N-R HES that could add value to renewable resources that are increasing in the State. A proposal to H2@Scale involving NuScale Power/UAMPS was promoted by Emery's Office.

INL is regularly invited to discuss the opportunities and benefits of nuclear energy at the annual Utah Governor's Energy Summit. Utah Science Technology and Research (USTAR) recently provided seed funding to a Utah Company to build a manufacturing capability for solid oxide

\footnotetext{
${ }^{5}$ See https://line.idaho.gov/ for more information.

${ }^{6}$ R. Cherry and R. Boardman, INL/EXT-12-27249
} 
electrolysis cell stacks (SOEC). INL is tracking this business activity because it relates to hydrogen production using high temperature heat provided by a nuclear reactor.

- Arizona continues to track the relevance of nuclear energy and hybrid energy systems. The Arizona Corporation Commission (AZCC) attended the first DOE-NE sponsored workshop on Nuclear-Renewable Hybrid Energy Systems held in 2014. ${ }^{7}$ Subsequently, INL Dr. Richard Boardman testified to the AZCC on the technical aspects of hybrid systems. The regional case study for APS may help shape AZCC policy relative to operation of the Palo Verde Generating Station.

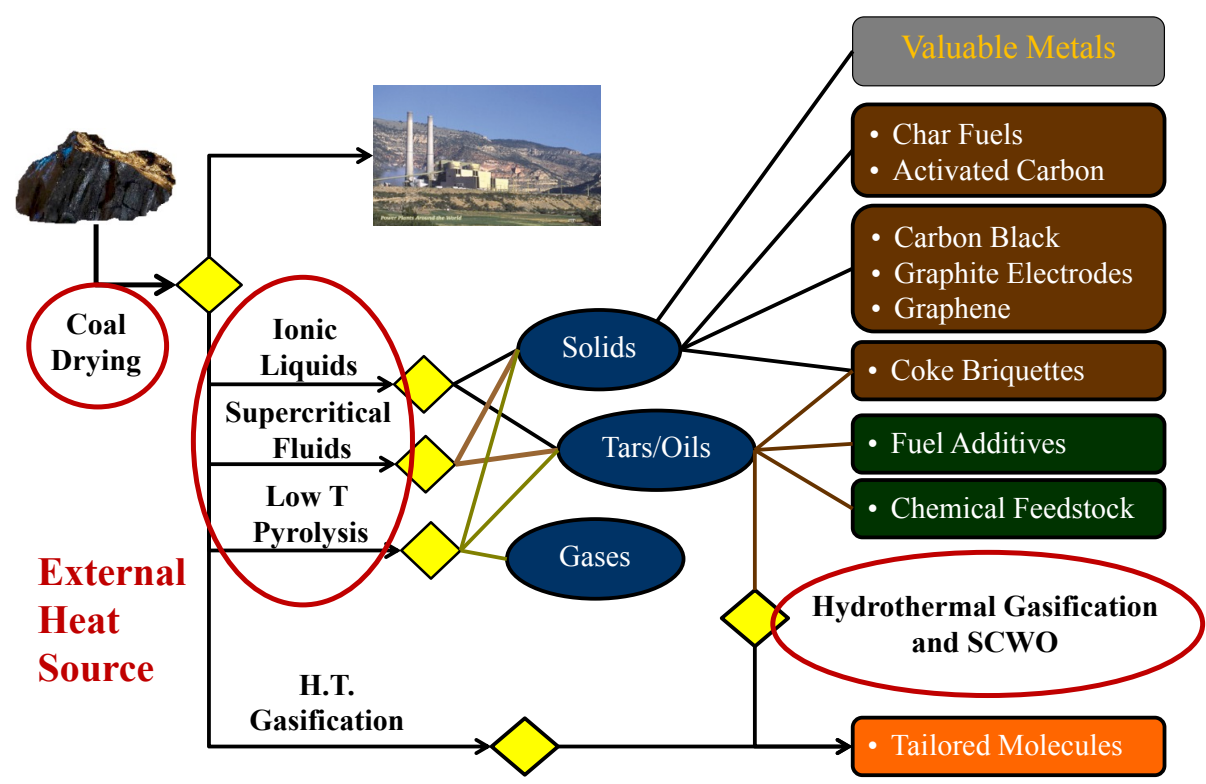

Figure 3. Illustration of opportunities to use nuclear heat to upgrade coal.

\subsection{University Partners}

University partnerships provide value to the N-R HES Program in both a direct and indirect manner. Direct work is being performed through student interns at the participating laboratories and through university subcontracts. It is anticipated that future work may be supported via the Nuclear Energy University Programs (NEUP) via the FY18 Consolidated Innovative Nuclear Research Funding Opportunity Announcement issued in October 2018. Indirect support is provided by related N-R HES studies funded by internal LDRDs (for long-range topics) and CRADA/SPPs. The N-R HES program leads ensure that activities supported by indirect funding are not dependent on direct program funding and vice versa.

Programmatic activities supported by university partners, to date, have focused on developing an overview of energy storage options for nuclear systems, premature shutdown of nuclear assets in the U.S., and a more global view on the future of nuclear energy in a proposed carbon-constrained world, where the latter two bring in aspects of energy policy and regulatory oversight. Indirect project results are provided to the N-R HES Program, unless a project is subject to a Non-Disclosure Agreement.

\footnotetext{
${ }^{7}$ S. Bragg-Sitton, et al., Integrated Nuclear-Renewable Energy Systems: Foundational Workshop Report, INL/EXT-14-32857 Rev. 1, NREL/TP-6A20-62778, August 2014.
} 
Direct project support is presently provided to Massachusetts Institute of Technology (MIT) for activities that are defined in the Project. This work has mainly been relegated to workshops and studies pertaining to the future value of nuclear energy and thermal energy storage that can increase the revenue of nuclear reactor operations in regions with relatively high penetration of renewable energy. The following workshops are noteworthy:

- LWR Heat Storage for Peak Power and Increased Revenue, June 27-28, 2017, Cambridge, Massachusetts. [Note: This workshop was sponsored by INL through the National University Consortium, and was attended by selected members of the N-R HES technical staff].

- $\quad 1^{\text {st }}$ US-Japan Workshop on the Future of Nuclear Energy in 2016, September 15-16, 2016, Cambridge, Massachusetts.

MIT also completed a joint study with Japan that examined the implications of renewables and deregulation on decisions for shutdown of existing nuclear plants and new build decisions in Japan and the United States (note that program funding was only provided to MIT for this study; contributions from the Japanese participants were supported by their home institutions). The U.S. and Japan face similar challenges, with some important differences that impact how these challenges are addressed. A report on this study was provided to the program in September $2017 .{ }^{8}$ This report, which was developed by MIT and collaborators from various institutions in Japan, summarizes the potential future of nuclear power in meeting low-carbon energy system requirements, specifically in the context of the U.S. and Japan. This report is currently under review by the Japanese co-authors and their respective institutions; the final version of the report will be issued upon approval of all authors. A final meeting with Japanese contributors is anticipated for December 2017 at MIT.

In connection with the joint MIT-Japan studies, a MIT PhD thesis on the premature closure of nuclear plants was also completed as a milestone under the N-R HES project. ${ }^{9}$ This thesis met the deliverable requirements for deliverable M4CT-17IN1201025. The thesis work developed two new tools aimed at measuring nuclear competitiveness and informing retirement strategies: (1) a structural model of electricity markets based on supply and demand equilibrium and (2) a long-term asset valuation framework accounting for stochastic price dynamics and flexible retirement options. MIT has employed employ these tools to analyze the challenges facing nuclear energy in the U.S. and Japan. After evaluating the drivers and likelihood of premature retirements, a range of technological innovations and regulatory options that could help nuclear bring value to future competitive markets is discussed. Overall, this research highlights the fact that the carbon-free attributes of nuclear energy are not valued in competitive markets. However, even a moderate price on carbon would save most plants from shutdown. If not possible, States may adopt nuclear subsidies to meet their policy objectives. As a last resort, the exercise of a new "mothballing" license could prevent the irreversible loss of nuclear assets.

The studies by MIT have relevance to understanding the impact of renewable energy given policy drivers, and the technical requirements placed on nuclear reactors that must operate as dispatachable generators. These works provide justification for re-assessing the viability and role of nuclear power plants in a transitioning energy sector.

A subcontract was issued to the University of Texas at Austin (UT) to support an INL-UT evaluation of energy storage options for nuclear power, following initiation of work via a summer student internship in 2016. The initial evaluation explores the possibility that a wide variety of energy storage devices could be integrated with advanced nuclear power plant (A-NPP) to provide flexibility. The report asserts that multiple factors could improve the economics of A-NPPs, including: (1) minimizing the need for active

\footnotetext{
${ }^{8}$ Forsberg, C., Omoto, A., Lester, R., et al., MIT-Japan Study: Future of Nuclear Power in a Low-Carbon World: The Need for Dispatchable Energy, MIT-ANP-TR-171, M4CT-17IN1201023.

${ }^{9}$ Haratyk, G., Nuclear Asset Shutdown Under Uncertainty, PhD Dissertation, Massachusetts Institute of Technology, submitted September 1, 2017
} 
safety systems, (2) minimizing adoption of one-off reactor designs, (3) establishing policies that credit low carbon emitting technologies, and (4) integrating energy storage technologies that increase revenue and reduce costs through a combination of ancillary services, market hedging, and reduced costs via stable operation. This study focuses on Item (4), containing an overview, synthesis, and examination of energy storage options that could be integrated with nuclear generation.

A down-selection tool was developed as a part of the initial UT research to help the user decide which technology is most appropriate. Some of the key factors considered by the tool include: environmental impact, geographic availability, cost requirements, technology maturity, and technology performance. The down-selection tool is capable of systematically considering data gathered in this report to generate a few top-level technology recommendations. ${ }^{10}$

A research activity was also extended to Ted Baker, a PhD student at The George Washington University (GWU) in Washington D.C. following an internship at INL. This research supports development and use of the INL RAVEN platform to support system design and operational control optimization for N-R HES. This activity has helped advance dynamic energy systems modeling and analysis to capture the value of flexibility by performing parametric analysis, as well as stochastic optimization to quantify the contributions of flexible loads and energy. This effort found that flexible systems may initially be more expensive, but have the potential to stabilize the levelized cost of electricity (LCOE) in the face of increased volatility in the load, represented by net demand with increasing wind energy. A journal article on the results of this study has been submitted to Elsevier. ${ }^{11}$

\section{International Activities}

Involvement in the international research community is critical to maintaining U.S. leadership in the development and deployment of advanced nuclear technology. DOE maintains participation in a variety of international committees and supports bilateral research agreements across a wide range of topics to ensure that the U.S. is aware of international research and has a voice in the various discussions on these topics. Recent international activities related to the N-R HES work are summarized below.

\subsection{International Committees / Expert Groups}

The Nuclear Energy Agency (NEA) and the International Atomic Energy Agency (IAEA) organized a workshop on the technical and economic assessment of non-electric applications of nuclear energy in April 2013. This workshop addressed the topics of district heating, desalination, high-temperature applications (process heat and hydrogen production), hybrid energy systems combining nuclear power and renewable technologies, and economic modelling. Following that workshop, the NEA supported an activity to develop a more standardized methodology for assessing the economic case for nuclear cogeneration. As a part of this effort, Dr. Cristian Rabiti (INL) was invited to join an ad-hoc OECD NEA Expert Group on the Role and Economics of Nuclear Cogeneration in a Low-Carbon Energy Future by the committee Secretariat Dr. Henri Paillere. Dr. Rabiti was able to attend the final two expert group meetings and to then provide input to the OECD NEA report that is currently being reviewed by expert group members. Participation in the Expert Group ensured that the U.S. view on cogeneration systems is represented in this final report, and more broadly disseminates U.S. R\&D in this topical area. Further details on the objectives and scope for the Expert Group can be found on the NEA website. ${ }^{12}$

\footnotetext{
${ }^{10}$ Coleman, J., et al., An Evaluation of Energy Storage Options for Nuclear Power, INL/EXT-17-42420, June 2017, available at https://www.osti.gov/scitech/servlets/purl/1372488.

${ }^{11}$ Baker, T. et al, “Optimizing Subsystem Capacity for a Nuclear Renewable Hybrid Energy System Using RAVEN," Preprint submitted to Elsevier, August 17, 2017.

${ }^{12}$ Ad hoc Expert Group on the Role and Economics of Nuclear Co-generation in a Low-carbon Energy Future (COGEN), https://www.oecd-nea.org/ndd/groups/cogen.html.
} 
The DOE-NE research on N-R HES was also presented to the OECD NEA Nuclear Innovation 2050 (NI2050) committee in April 2016 (via teleconference). The presentation was well-received by the committee members, with many questions asked to clarify motivations, scope and status. Discussion with NI2050 committee chair Marc Defrennes in April 2017 indicated that nuclear hybrid energy systems is called out in the draft NI2050 Roadmap as a medium to long-term technology option. NI2050 was launched via workshop at OECD Headquarters in Paris in July 2015, bringing together leading experts in nuclear fission RD\&D. NI2050 is designed to help set global nuclear fission R\&D priorities and foster their implementation, and to identify opportunities for enhanced cooperation. Key goals in topics selected for inclusion in NI2050 use innovation to achieve economic viability, enhanced safety, and public acceptance. Descriptions for topics selected for inclusion in NI2050 are anticipated by the end of 2017, with stakeholders being assembled in 2018. More information on NI2050 can be found at https://www.oecd-nea.org/ndd/ni2050/.

\subsection{International Workshops}

International Workshop on Pathways to Deep Decarbonization - Synergies Between Nuclear and Renewable Energy (June 2016): An international workshop was held June 9-10, 2016 at the National Renewable Energy Laboratory facilities in Golden, CO. This workshop was organized and supported with discretionary INL Program Development funds and NREL Joint Institute for Strategic Analysis (JISEA), but was coordinated with the N-R HES project leads. Dr. Pete Lyons (ret. DOE-NE) chaired the workshop; Dr. Mark Peters (INL) welcomed the participants and participated in the full 1.5 day agenda. Key DOE-HQ participants included Suibel Schuppner (NE), Steve Capanna (EERE) and Carla Frisch (EPSA). Total attendance was limited to $\sim 60$. International participants included OECD/NEA, IAEA, CEA (France), U. of Leuven (Belguim), CAS/SARI and CAS/SINAP (China), INET (China), Canadian Nuclear Laboratories, JAEA (Japan), and the Jordan Atomic Energy Commission. US attendees included INL, ORNL, NREL, SNL, NuScale, TerraPower, Terrestrial Energy, NGNP Alliance, EPRI, Exelon, E3, Third Way, Evolved Energy Research, MIT, and Colorado School of Mines.

Synergies crossing electricity, transportation, and industrial sectors were the focus of the workshop, recognizing that significant emission reduction will require efforts that go far beyond the electricity sector alone. The workshop brought together international researchers from the many disciplines that would be involved in designing, demonstrating, and implementing the proposed nuclear-renewable hybrid energy systems. The end goal was to begin discussion on a potential framework for increased international cooperation to explore these synergies and to accelerate the quest for significant reductions in emission of greenhouse gases that would enable decarbonization of the energy sector.

A report on the workshop was issued, ${ }^{13}$ and all presentations that were publicly released are posted to the meeting website via hyperlinks on the Agenda. ${ }^{14}$ The workshop resulted in agreement to meet again 2017, possibly in China, and all organizations resolved to collaborate. Due to current U.S. restrictions on travel to and collaborations with China, the follow-on workshop was put on hold. A proposal to host a follow-on workshop in Canada was received verbally in October 2017 by leadership at the Candian Nuclear Laboratories.

\section{$8^{\text {th }}$ International Symposium on Advanced Energy Science Kyoto University (September 2017):} Dr. Shannon Bragg-Sitton participated as an invited speaker at the $8^{\text {th }}$ International Symposium on Advanced Energy Science organized and hosted by Kyoto University (Japan). Note that all travel costs for this participation were borne by Kyoto University. The invited presentation, entitled "Development of Flexible Nuclear Energy Systems in the U.S.," covered the broad status of nuclear energy in the U.S. and

\footnotetext{
${ }^{13}$ Bragg-Sitton, Boardman, Ruth, Lyons, International Workshop to Explore Synergies Between Nuclear and Renewable Energy Sources as a Key Component in Developing Pathways to Decarbonization of the Energy Sector, INL/EXT-16-39701, August 2016, available at https://www.osti.gov/scitech/biblio/1364488-workshop-report-international-workshop-exploresynergies-between-nuclear-renewable-energy-sources-key-component-developing-pathways-decarbonization-energy-sector

${ }^{14}$ https://snrworkshop.inl.gov/SitePages/Agenda.aspx
} 
then focused more specifically on the need for flexible energy systems, which can be met by proposed nuclear hybrid energy systems. Many activities associated with the development of advanced fission systems have been put on hold in Japan following the 2011 Fukushima Daiichi accident, but researchers at Kyoto University are currently investigating fusion applications of the hybrid energy system concepts.

Dr. Bragg-Sitton was additionally asked to participate in a panel discussion at the Symposium entitled "Interdisciplinary Approach to Zero-Emission Energy." Each of the panelists was asked to address the question of how we can best communicate across diverse academic fields to achieve the common target of a sustainable society within specific studies that we lead. Panelists, along with their respective affiliations and fields of expertise, included:

- Shannon M. Bragg-Sitton (Idaho National Laboratory) / Nuclear Energy

- Deliang Yu (Southwestern Institute of Physics) / Plasma Physics

- Claus Felby (University of Copenhagen) / Bioenergy

- Seunghyun Baik (Sungkyunkwan University) / Nano Science

- Dihua Wang (Wuhan University) / Solar Energy Materials

- Satoshi Konishi (Kyoto University) / Fusion, Sustainability (session moderator)

Nuclear and Renewable Energy Resources 2018 (NURER2018, Sept-Oct 2018): The $6^{\text {th }}$ International Conference on Nuclear and Renewable Energy Resources (NURER2018), which will be held in Jeju, Korea September 30 - October 2, 2018, is recognized as one of the major international conference for the exchange of information on scientific, engineering, and other technical aspects of innovative nuclear and renewable energy science and technology. ${ }^{15}$ The conference is intended to provide an excellent opportunity to report on recent technical progress, discuss key issues and fostering international collaboration for the promotion of innovative nuclear and renewable energy system development and their synergic collaborations. Papers related to science, engineering, facilities, experiments, modeling, analysis, design and safety are currently being solicited. Dr. Shannon BraggSitton has been invited to serve as a Technical Program co-Chair for NURER2018 and to provide a plenary talk for the conference.

\subsection{India}

Drs. Shannon Bragg-Sitton and Carl Stoots (INL) participated in the U.S.-India Civil Nuclear Energy Working Group (CNEWG) and U.S.-India Workshop on Hybrid Energy Systems and Hydrogen, held at the India Department of Atomic Energy (DAE) in Mumbai, India August 7-10, 2017. Both nuclear hybrid energy systems and hydrogen generation via nuclear systems were offered as points of collaboration with India in December 2015 under the CNEWG. Although a few video conferences were held prior to this meeting, no official collaboration had been defined for the HES and $\mathrm{H} 2$ research areas. The full day HES and hydrogen workshop was organized to clarify the breadth and depth of the work being conducted in each country in order to better define points of collaboration. This workshop was originally scheduled for March 2017 but was later rescheduled to coincide with the annual CNEWG meeting due to a conflict that arose for the March meeting. A collaborative proposal was formulated to address the integration of nuclear hybrid energy systems for cogeneration of electricity, hydrogen and potable water. In doing so, it was proposed to combine the previously separate collaborations on HES and hydrogen into a single collaborative project. The complementary potential of coupling desalination with nuclear was recognized and added to the collaboration. Note that travel costs for this meeting were borne by DOE NE-6 International Programs.

\footnotetext{
${ }^{15}$ Additional information on NURER2018 can be found at http://media.journals.elsevier.com/content/files/nurer201807093409.pdf
} 


\subsection{China}

INL has invested in a relationship with China to collaborate on hybrid energy systems dating back to 2008 following meetings with organizations and universities developing nuclear energy in China. This effort led to a series of reciprocal visits with the Shanghai Branch of the Chinese Academy of Science (CAS). A DOE-CAS agreement for Nuclear Energy Sciences and Technologies (NEST) cooperation was initiated in 2014. This agreement included cooperation on Nuclear Hybrid Energy Systems.

This cooperation helped facilitate several meetings with the INL N-R HES team and U.S. commercial developers of nuclear energy. Currently, this activity has been put on hold. INL and the Shanghai Institute for Nuclear and Applied Physics (SINAP) and the Shanghai Advanced Research Institute (SARI) will

continue to discuss mutual interests in high temperature steam electrolysis and chemical manufacturing as it pertains to use of clean energy sources, but these interactions will not include nuclear technology development. 